......- CAPÍTULO 1

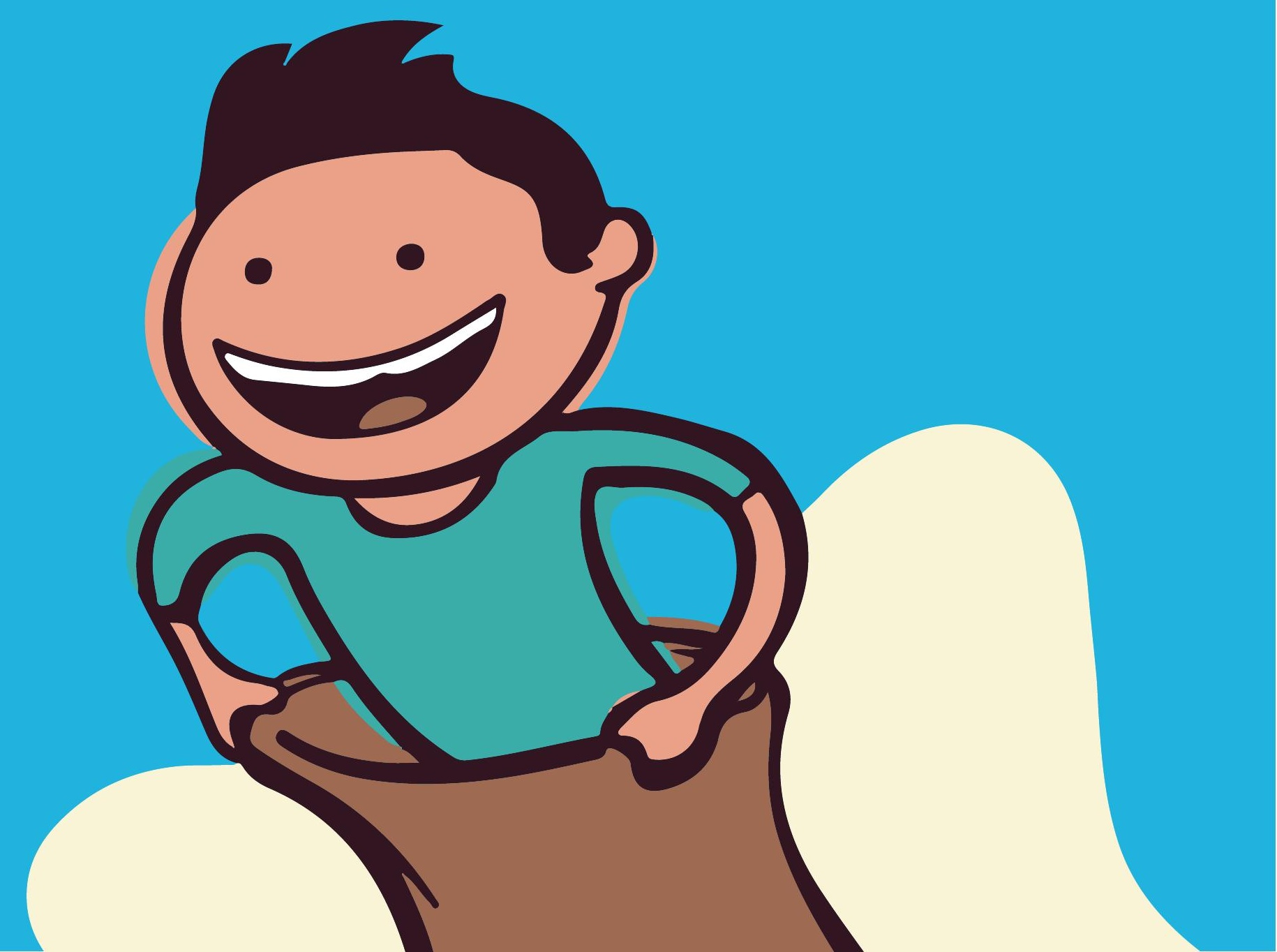




\section{El juego en el desarrollo infantil desde las ludotecas NAVES}

En este capítulo se acercará al lector

a una serie de elementos teóricos

y conceptuales respecto al lugar que ocupa el juego en el desarrollo humano $y$, en particular, en el desarrollo infantil, desde los cuales se plantea la acción metodológica de las ludotecas Naves (niños, niñas aprendiendo, viviendo,experimentando y socializando) en los diferentes contextos y territorios donde se implementan.

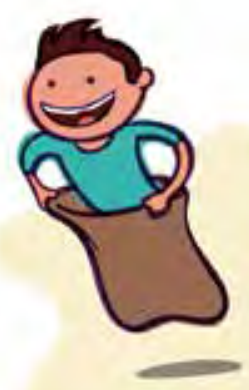


Entender el juego desde enfoques diversos implica analizar las múltiples miradas desde las cuales se establecen relaciones directas con el desarrollo y se logra entender como un elemento fundamental de la existencia humana, tal como lo plantea Eugen Fink (1993), al darle un lugar determinante en la vida del ser humano y en su desarrollo. Pero si reflexionamos un momento en eso de ser un elemento fundamental de la existencia humana, inmediatamente nos encontramos con la pregunta sobre el jugar: ¿qué definimos como juego?, ¿qué entendemos por jugar?, por qué jugamos? Son preguntas que cada uno puede responder desde su propia vivencia porque todos tenemos nuestra propia experiencia de juego: jugamos en la plaza, en el patio, en la habitación, en el barrio, en la escuela, en el hospital, en la ludoteca. Jugamos con amigos, con no amigos, con conocidos, con desconocidos, con la familia, con los lejanos. Jugamos con un juguete perfectamente elaborado o con un convencional lapicero que se convirtió desprevenidamente en juguete al dibujar sobre un papel trazos con sentido solo para quien raya. Jugamos solos cuando vamos por la calle sin pisar raya o jugamos con otros cuando esto es posible. Jugamos cuando niños tratando de inventar un nuevo modo de vivir y jugamos cuando adultos tratando de salirnos de ese modo de vivir construido. Jugamos sin un objetivo definido, pero con el más alto sentido del regocijo por la vida misma, por la alegría, por la diversión inocente o por la más elaborada pasión irreverente de disfrute y búsqueda de la felicidad.

Visto esto así, tratar de definir el juego no es una tarea fácil, por cuanto cada vez que se plantea la sola palabra "jugar" se entiende de modo diferente de acuerdo con el lugar desde el cual se hace la pregunta o el lugar desde el cual cada uno se juega su respuesta. Por ejemplo, al revisarlo desde el lugar de la educación en el imaginario común aparece como un elemento central del aprendizaje, pero al analizarlo desde un enfoque psicológico aparece como un 
factor de descarga de energía, de exploración y manifestación de la personalidad, etcétera.

La dificultad para definir el juego aumenta cuando se percibe que un mismo comportamiento puede ser visto como juego o no juego según quien lo observe o lo viva. Por ejemplo, si se para un observador externo cerca de un niño indígena que se divierte lanzando con su arco y flecha a un pequeño animal, lo ve como un juego. Para la comunidad indígena nada más es una forma de preparación para el arte de caza necesaria para la subsistencia de la tribu. Así, el lanzar una flecha con el arco, para uno, es un juego, para otros es preparación del oficio. (Kishimoto, 2011, p.14)

Visto así, tratar de definir el juego no es una tarea sencilla; sin embargo, para darle una comprensión amplia que salga del ámbito personal es preciso analizarlo desde sus múltiples facetas y desde los diversos enfoques a partir de los cuales se ha analizado a lo largo de la historia del hombre, los cuales van desde una visión antropológica, pasando por la filosófica y psicológica hasta llegar a una visión educativa del juego, lo cual permite acercarnos a un ejercicio profundo de las diferentes comprensiones sobre el juego, desde las cuales se puede establecer un panorama amplio e integral del lugar que ocupa este en el desarrollo integral de los niños y las niñas, en el desarrollo social y el desarrollo humano.

Desde el enfoque antropológico del juego, el cual lo plantea como un elemento central de la cultura y de la evolución del hombre y su cultura, se encuentra la teoría expuesta por Huizinga (1972), Caillois (1986), y Vidart (1995), quienes muestran, desde diferentes aristas, la naturaleza del juego, el entramado que teje con la cultura y las culturas, la forma en la cual es capaz de anticipar la cultura en los juegos de la infancia hasta atreverse a afirmar, como lo haría Hui-

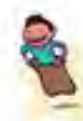


zinga, que la civilización surge del juego. Pues bien, juego y cultura se desarrollan en una estrecha relación que es permanente y que emerge desde una misma dimensión del ser humano: la dimensión lúdica. Dentro de esta dimensión, el juego, en tiempos de la antigüedad clásica, era puesto en escena y estudiado como un elemento de crianza con el cual era posible desarrollar disciplina en el niño o niña y, por lo tanto, era puesto en escena como un factor de formación en las habilidades para vivir en sociedad (valores), que estaba en íntima relación con la manera como la sociedad establecía un orden o la manera como se orientaba al ciudadano que se quería para los pueblos. Por lo tanto, existía una "interesante vinculación entre juegos, saberes y prácticas" (Enriz, 2011, p.95).

De acuerdo con Brougere (2013), el juego es una manifestación clara de las culturas en tanto muestra la manera en la cual se desarrollan desde tres aspectos centrales: primero, sobre la manera en la cual se establecen las reglas del juego, las cuales corresponden, en gran medida, a la manera como en los grupos sociales se van configurando y las formas en las cuales establecen las relaciones y las maneras de convivir; segundo, sobre las maneras en las cuales se juega esas reglas interpretándolas a partir del momento histórico en el que se dan, es decir, se juega de una manera dependiendo de la época en la cual el juego se desarrolla; y tercero, los materiales de juego (juguetes), los cuales son una muestra de las producciones de la cultura, de su momento histórico y de la manera en la cual se interpreta o se percibe la realidad. Un ejemplo de esto son las muñecas, las cuales reflejan la forma en la cual se muestran los hombres y mujeres de cada época. Desde la antropología, el juguete es un elemento muy importante en tanto muestra cómo fueron las culturas de los tiempos pasados, su vestimenta, sus objetos, sus maneras de percibirse, los colores, los materiales y las formas.

En este enfoque se deja ver una importante diferencia entre el juego y el jugar, entendiendo el juego como un esquema sociocultural que tiene significa- 
ción propia, como lo propone Mantilla (1991), y el jugar como la acción de hacer esa representación, la cual implica movimiento interno y externo del cuerpo y de la mente, en tanto hay expresión, gesto, cambio, tensión, distensión, alegría, concentración, vida. Esto nos hace adentrar en la idea de que el juego en la cultura y en la historia del hombre no está atado a otras necesidades vitales, por lo tanto, no es necesario entender el por qué y para qué jugar, sino comprender el sentido del juego en sí mismo, en su propia extensión.

Desde el enfoque psicológico, autores como Groos, Freud, Piaget y Erikson lo plantean de diversas maneras; como fenómeno de preparación a la vida adulta, como la mejor manera que expresa el principio del placer, como una manifestación de la inteligencia del niño y de la evolución de sus capacidades, como la sublimación de la energía del ser humano, como manifestación comportamental que da lugar a cambios o tránsitos en la personalidad y, en especial Winnicot (1982), lo plantea como el espacio potencial, el lugar del ser humano que no está dentro ni fuera, que no es realidad pero tampoco es ficticio totalmente, ese espacio potencial donde el ser humano es capaz de crear. Solo en el juego el niño o el adulto están en libertad de ser creadores en ese espacio potencial en el cual la confianza cumple un papel fundamental, la cual se desarrolla a partir del vínculo de seguridad establecido con la madre.

Este enfoque psicológico del juego presenta dos características comunes: por un lado, el principio de libertad del juego, pues cada jugador es libre de decidir si juega o no, o simplemente si lo hace o no, y aunque se obligue a hacerlo el jugador entra en el juego cuando, desde su propia voluntad, decide hacerlo. Una segunda característica común en este enfoque psicológico es plantearlo como una manifestación de la inteligencia, lo que está íntimamente relacionado con el desarrollo cognitivo del ser humano. Según las diversas teorías psicológicas, jugar implica un compromiso de las capacidades cognitivas, como análisis, de-

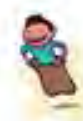


ducción, inducción, reflexión, entre otras que hacen parte determinante en el desarrollo del pensamiento y conocimiento de cada persona.

Por lo tanto, el enfoque psicológico del juego relaciona de manera directa el desarrollo del comportamiento humano con la forma en la cual se desarrolló el juego infantil; de hecho, desde este enfoque, el juego tiene el poder de mostrar lo que sucede con los niños y las niñas, su personalidad, su carácter, lo que está pasando en su vida y las formas en las cuales se está relacionando consigo mismo y los otros.

Desde un enfoque social, el juego es planteado como un moderador del comportamiento colectivo y como la mejor posibilidad para relacionarse con los otros. En este sentido, en el juego aparece la norma, la cual le confiere al juego uno de sus más innegables rasgos: no contradice su libertad y espontaneidad, pero la regula, y esto le imprime incluso un mayor grado de emoción al jugador. La regla define el contexto del juego, su tiempo, su espacio, su orden. La regla es lo que le imprime al juego el reto, la necesidad de superarlo y lograr un reto mayor. Es lo que le otorga la excitación de lo que hay que cuidar y a la vez superar. La regla es silenciosa y bulliciosa a la vez, está ahí para que no se quebrante, y si lo hace, lanza un grito de alerta que emociona al juego y al jugador. Cuando se juega con otro es la regla lo que nos iguala, hace equitativo y justo el objetivo y la forma para llegar a él. Esto es lo que va creando o configurando una relación, es decir, un campo social, un campo de relación con los otros.

Las reglas deben ser aceptadas y respetadas por todos los jugadores para que el juego pueda comenzar y seguir su desarrollo. Aquel jugador que no respete las mismas es el denominado "aguafiestas". Es preciso hacer una diferencia entre aguafiestas y tramposo. En el primer caso, se crea una ruptura 
del juego, en cambio el tramposo aparenta estar dentro del círculo mágico del juego (Tirado, 1998).

La regla le otorga un amplio sentido social al juego. Se configura una sociedad cuando se juega. Una estrecha relación en la cual los jugadores aceptan unas maneras de estar y de hacer las cosas. Unas formas de actuación que las delinea el juego mismo. Por ejemplo, no es posible jugar golosa (rayuela, peregrina, avión), de una manera distinta a la que el juego se ha acordado cultural y socialmente. Al ser un acuerdo social, quien acepta jugar acepta las reglas que el juego tiene, o las reglas que se van creando en torno al juego, aun aquellos juegos que parecieran no tenerlas, como aquellos que espontáneamente se van construyendo. Un ejemplo de esto son los juegos que hacen los niños en las habitaciones de la casa: se van creando castillos, caminos, vehículos, etc. Al irse creando, van delineando sus espacios, los cuales no pueden transgredirse: la puerta por la cual se entra al castillo es la que se definió en el juego, por lo tanto, aunque un jugar desprevenido pudiese entrar por otro lugar, aquellos que han constituido la puerta advierten que "por ahí no es"; si alguien quisiera pasar caminando un río acordado en el juego, el grupo inmediatamente advertirá el riesgo que tiene de ahogarse.

Otro elemento que vale la pena analizar sobre el enfoque social es el carácter competitivo 0, como lo diría Caillois (1986), el carácter agonal del juego. Pues bien, esta característica es lo que le exige al juego hacerse con otro o con otros, por lo tanto, el juego reconoce "la otredad", pues el rival, aunque lo sea, se necesita. Desde esta perspectiva, el juego se hermana con el deporte, con la diferencia que en el juego ganar o perder es una opción legítimamente considerada, en cambio, en el deporte, perder es la opción no esperada. En ambos casos, ganar es lo deseado y en ambos casos el rival es necesario, pues en el competir con otro u otros está parte de lo vertiginoso y divertido del juego. Si

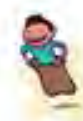


bien se puede competir consigo mismo, por ejemplo, en un juego de solitario, el saberse compitiendo con otros implica un mayor grado de compromiso con el juego mismo y un mayor grado de esfuerzo en las capacidades que se ponen en escena por parte del jugador.

El juego, desde este enfoque social, vincula a los jugadores, estrecha relaciones, desarrolla vínculos, afectos, rivalidades, cercanías. Constituye un lugar de privilegio para estar con los otros de una manera que reta las capacidades sociales y logra afirmar la personalidad de cada persona cuando está y convive con otros.

Desde el enfoque filosófico, el juego es analizado incluso en un lugar ausente del jugador. El juego es en sí mismo y hace parte no solamente de la condición humana, sino de la existencia misma. Esta compresión implica entender la inutilidad del juego, como lo plantearía Scheines (1998), el juego se agota en sí mismo, es total y no algo que espera ser completado. Es una actividad de aquí y ahora. Una isla desconectada del pasado y del futuro. El juego es todo el mundo, lo demás no existe mientras se juega.

Desde este enfoque, también se plantean las posturas de Caillois (1986), Duvignaud (1982) y Gadamer (1991, 2001), quienes plantean el juego como la ausencia de producción de un producto, la perspectiva de la nada, un movimiento constante de ida y vuelta, un constante vaivén sin un fin determinado.

El juego tiene un modo de ser propio, total, particular, en una relación analógica permanente de lo objetivo y subjetivo, en donde el verdadero sujeto del juego es el juego mismo. No requiere de un jugador para ser juego, lo que le otorga el carácter atractivo, pues es desde el ser del juego que los sujetos se sienten atraídos a jugar o a entrar en el juego como observadores. Esto se 
explica en un juego de ajedrez (bolas de cristal), en donde el juego transcurre incluso en el silencio y seriedad de quien juega. El espacio de juego tiene un propio movimiento, y si hay alguien observando el juego, este disfruta el ser de ese juego aun sin jugarlo. Tiene otro lugar que lo atrae y hace que permanezca de pie, viendo los movimientos de las fichas. Pero en este juego, también quienes juegan entran en una realidad paralela de la que ellos mismos no son conscientes y solo se interrumpe cuando la partida termina, y es cuando se retorna a la otra realidad en la que el juego no está.

Por último, desde un enfoque educativo, se plantean las maneras de entender el juego como elemento central de la función educativa, siempre que el docente lo introduzca como parte de su práctica pedagógica, comprendiéndolo como una acción desde la cual los contenidos pueden ser intencionados o no, pero vividos y experimentados.

Cuando el juego se "formaliza" en algunos espacios, especialmente en los educativos, tiende a adquirir diferentes funciones. Así, el juego es un recurso para enseñar, una actividad por la que los niños se sienten "naturalmente" atraídos, un medio para llamar la atención. El juego es el momento libre de la escuela en el recreo o en los días de lluvia, cuando la ausencia de los niños no permite iniciar contenidos nuevos. Los niños solicitan jugar y el "no jugar" se transforma en una forma de castigo para los grupos. Algunos contenidos se enseñan con juegos y a otros es imposible atravesarlos por lo lúdico. (Sarlé, 2010, p.19)

El juego constituye un modo fundamental por medio del cual los niños paulatinamente llegan a formar una representación de una actividad en la que se especifican todos los objetos, las acciones y sus interrelaciones. 
En los primeros juegos individuales, los niños ponen de manifiesto aquello que han podido abstraer de las diferentes situaciones de la vida cotidiana. Las representaciones mentales que va desarrollando el niño "constituyen un sistema de conocimientos del mundo, que funciona como un "contexto cognitivo" desde el cual el niño interpreta lo que otros hacen y dicen y construye un nuevo conocimiento" (Sarlé, 2010, p.44).

Para Pavia (2018), el contexto de la escuela es propio para el juego, en especial el tránsito para su llegada y el patio para el recreo. El acto educativo allí se materializa cuando el docente -pedagogo observa. La escuela no es solamente un establecimiento en donde se imparte enseñanza. La vieja escuela constituye aun hoy un punto privilegiado de encuentro al que los niños asisten con la renovada expectativa de cruzarse con sus pares. Pensemos también que buena parte de esos rituales de encuentro "sucede en los patios bajo la forma genérica e imprecisa de juegos" (Pavia, 2018, p.154).

Para Sátiro (De Puig \& Sátiro, 2011; Sátiro, 2006), desde la filosofía para niños, el juego es la fórmula perfecta para favorecer que los infantes desarrollen el pensamiento creativo y postulen nuevas formas para transformar su vida y la vida de otros. Es la posibilidad para comprender, a partir de preguntas, su lugar en la familia, en la comunidad, en la escuela, en el mundo. El acto creativo inicia con el juego y con él las preguntas que dan lugar a la oportunidad de reflexionar y pensar sobre sí mismo, sobre el transcurrir de la vida y en especial de la vida humana y de la manera en la cual nos construimos como seres humanos.

Este primer acercamiento al juego y al jugar nos impulsa a continuar en la siguiente parte del capítulo, relacionándolo con el desarrollo infantil y, enseguida, con el desarrollo humano, lo cual resulta congruente con uno de los plantea- 
mientos iniciales que sugiere que, en el jugar, está la vida misma y, con esta, el desarrollo del ser humano.

\section{El juego y el desarrollo infantil}

Al respecto son muchos los análisis, investigaciones, planteamientos que se han hecho desde diversos lugares y teorías; todos coinciden en incorporar el juego como factor central del desarrollo infantil, no solo como elemento que da cuenta del propio desarrollo, según lo plantearía Piaget (1991), o como una manifestación que evoluciona en la medida que evoluciona la cultura, como lo diría Brougere (2013).

En efecto, el juego está íntimamente ligado al desarrollo de los niños y las niñas, pues es la forma en la cual los niños están en el mundo: durante el baño, los niños juegan imaginando ríos bajo sus pies o haciendo volar pompas de jabón o la sola espuma con aquel que lavan su cuerpo. Cuando se alimentan en el plato abren caminos para que la cuchara transite buscando entre los alimentos la magia del juego. Al irse a la escuela tomados de la mano del adulto que lo acompaña o transitando solos por el camino, van cuidadosamente tratando de no pisar raya o pateando la piedra que fantásticamente es el juguete que permite el juego, bajo la premisa de no dejarla perder del camino. Estando en clases hacen trazos sobre la última hoja del cuaderno, jugando con los trazos, las sombras, las líneas, las curvas o dibujando al profesor y, al llegar nuevamente a casa, cualquier momento es el preciso para jugar en el cuarto, en la cocina, en la sala, en el patio o, si la seguridad lo permite, en la calle. ¡Tal cual! El juego es la forma de estar los niños en el mundo. Para ellos es la vida misma y se juegan la vida de manera permanente.

Pero frente a esta "actividad, creativa, libre y placentera que permite vivir la transformación de la realidad", como lo define la Corporación Juego y Niñez

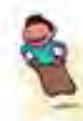




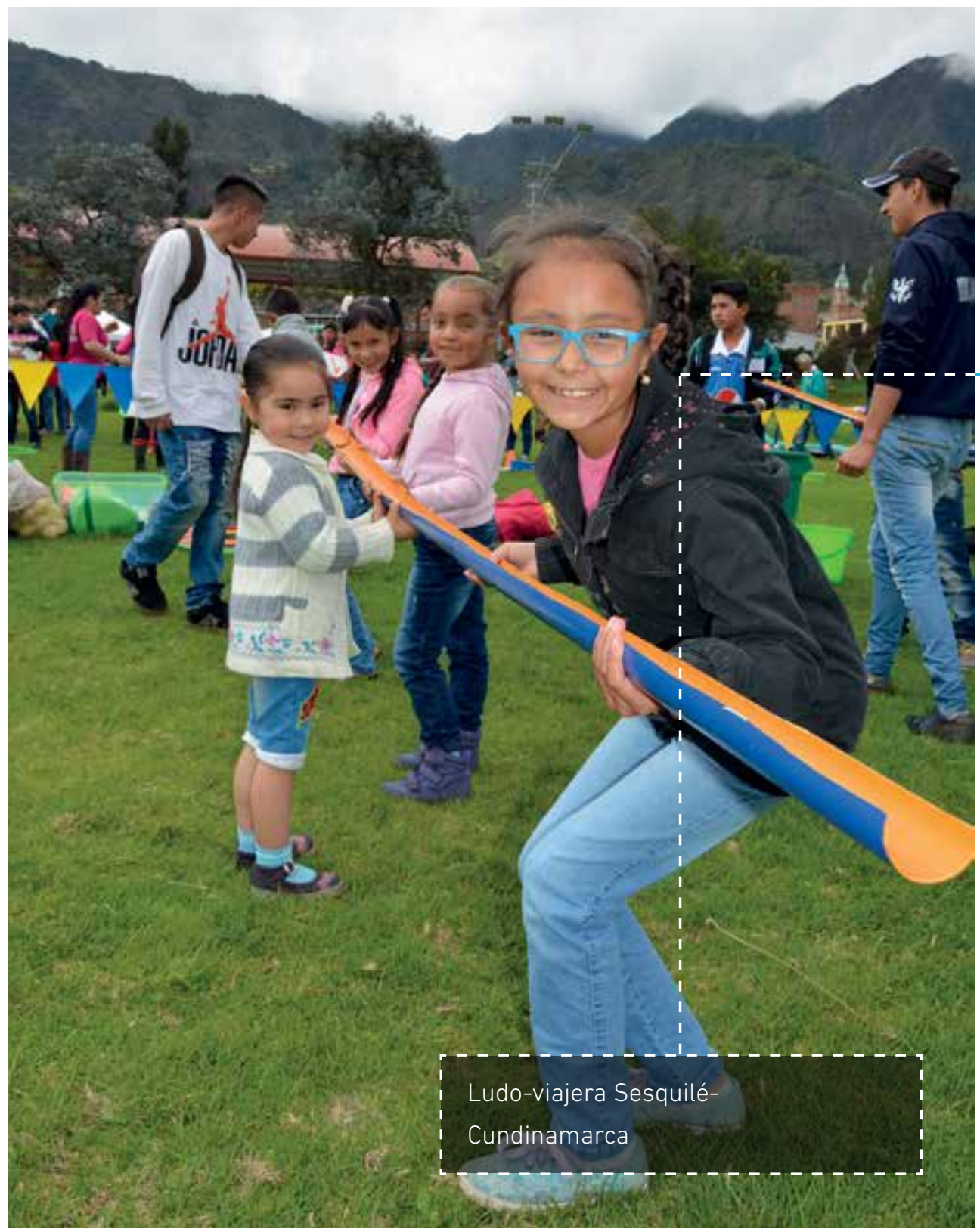


(2008), que, a ojo del adulto desprevenido y preocupado por la búsqueda permanente de la utilidad de las acciones y de ganarle tiempo a la vida, el juego es una actividad que produce divertimiento, pero que puede ser una pérdida de tiempo a no ser que aporte algo útil. Pues bien, si de eso se trata, es preciso decir que el juego, al ser una actividad presente de manera inmanente en la vida del ser humano, constituye un factor que determina o favorece el desarrollo de cada una de sus dimensiones.

Por ejemplo, el desarrollo de la dimensión corporal es posible en tanto el niño y la niña descubren, exploran, apropian y potencian su cuerpo y las capacidades que tiene de movimiento, flexibilidad, fuerza, resistencia, ubicación espacial, equilibrio, destreza, entre otras. Pues bien, estas capacidades y habilidades se desarrollan cuando se juega y en el juego se compromete el cuerpo: saltar la golosa, saltar lazo, trepar un árbol, jugar a las carreras, jugar a las estatuas, empujar carros de cartón, hacer girar el trompo, jugar una ronda, esconderse, salir corriendo en el "tin tin corre corre", y cientos de juegos de este tipo hacen que el niño y la niña conozca su cuerpo, lo explore, lo potencie y alcance el máximo potencial.

Otro ejemplo: la dimensión socioafectiva emerge en tanto el niño y la niña empiezan a desarrollar emociones y sentimientos sobre sí mismo y por los demás. Cuando comprende que se encuentra con otros que son sus cercanos en el mundo, con quienes tiene la posibilidad de construir vínculo, el cual inicia en la estrecha cercanía con la madre y que, poco a poco, se va trasladando a los apegos con objetos, juguetes y otras personas que van siendo parte de su entorno cercano. Sin embargo, es jugando cuando puede experimentar las emociones, afectos y relaciones que van a hacer parte de su desarrollo. Cuando el niño juega empieza el descubrimiento del mundo, pero al jugar con otro es cuando descubre el significado de convivir desarrollando sentimientos que van desde la alegría, la

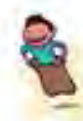


confianza, la placidez, hasta la frustración, el asombro, la ira, entre muchos otros que constituyen el amplio universo de afectos y desafectos que constituyen la dimensión socioafectiva en el ser humano. Con quienes se juega en la infancia se crea un vínculo afectivo que favorece las relaciones afirmativas y la capacidad del niño y la niña de establecer relaciones de amistad, respeto, aceptación de la diferencia y convivencia.

Respecto a la dimensión cognitiva, diremos que el juego permite la cognición, es decir, la capacidad de elaborar pensamiento a partir de la información que recibe de la realidad, a lo que se ha denominado percepción. En este sentido, la percepción permite incorporar y elaborar información, que lo hace de manera especial cuando juega. Es así como al empujar una pelota percibe la información sobre su forma y peso, y esto le permite intuir cuál es el mejor movimiento para lanzarla lejos de sí o hacerla rebotar para que vuelva a sus manos. Este pensamiento intuitivo, diría Piaget (1979), es lo que da lugar posteriormente al pensamiento operacional y luego a la abstracción. Cuando juega, el niño experimenta, se equivoca, acierta, intuye, analiza, infiere, calcula, concluye. Todas estas son capacidades de la dimensión cognitiva que comporta el pensamiento y el conocimiento.

Con relación a la dimensión comunicativa, es preciso decir que el juego es un lenguaje en sí mismo, en tanto expresa, sin el habla, lo que el niño o niña quiere comunicar, pero también, como lo plantearía Bruner (1983), el juego es la primera oportunidad y la primera actividad con la que el niño descubre que las palabras logran acciones; por ejemplo, si dice "pelota", sin necesidad de decir rodemos la pelota, el adulto entenderá que debe hacerlo y se inicia un juego en el que obtiene la acción que espera solo con nombrarse un objeto. Pero también cuando se reta el habla con las retahílas, los cantos, las rondas, los trabalenguas, las letras dichas y cantadas, esos juegos que encuentran en las palabras y en sus sonidos 
la mejor forma de retar el habla. Desde este análisis, el juego es un lenguaje que relaciona y vincula, estableciendo un diálogo propio, un diálogo lúdico que se encuentra en el disfrute, en el descubrimiento, en el reto, en la incertidumbre, en la seguridad, en la diversión, en la alegría, en la frustración. Pero, así como es un lenguaje en sí mismo, también es vehículo para el lenguaje, para el encuentro con las palabras, las frases, las ideas y las formas diversas del habla.

Pues bien, todas estas maneras de manifestarse el juego en el desarrollo de los niños y las niñas a través de las dimensiones del ser humano, las cuales están en una permanente interconexión en la cual no es posible fijar un límite entre la una y la otra, permiten concluir que el desarrollo infantil, proceso no lineal, único y diferente, se da a partir de los logros que se facilitan en el juego y en el cual el niño y la niña va logrando una serie de adquisiciones propias que no tienen la pretensión de lograrse, pero que se dan, pues el poder del juego se da en su espontaneidad y libertad. Cuando se juega no se va a hacer amigos, pero se hacen. Cuando se juega no se va a aprender de normas y acuerdos, pero se construyen y aprenden. Cuando los niños juegan no pretende desarrollar su pensamiento, pero lo logran. Al jugar, los niños no buscan conocer su cuerpo, pero lo descubren y lo retan. Cuando los niños juegan no piensan en desarrollar lenguaje, pero se comunican de manera inusitada con los otros. Al jugar, los niños no buscan insertarse en la cultura, pero lo hacen. La construyen, deconstruyen y la transforman. Cuando los niños juegan no buscan ser creativos, pero crean, recrean, imaginan y transforman. Pues bien, el juego nos asombra con sus miles de posibilidades y nos invita a reflexionar en que cuando el ser humano juega, se juega la vida misma en la alegría y la seriedad que le exige el jugar.

\section{El juego, las ludotecas y el desarrollo humano}

Si bien el concepto de desarrollo humano se viene abordando desde miradas alternativas a partir de las propuestas desarrolladas por Amartya Sen (1999), Max

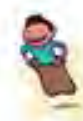


Neef (Max-Neef, Elizalde, \& Hopenhayn, 1986), y Martha Nussbaum (2010), tradicionalmente había sido abordado principalmente por las ciencias económicas desde un enfoque que fundamentaba una teoría que homologaba el desarrollo humano con el desarrollo económico de las personas, los pueblos y los países.

\begin{abstract}
El enfoque economicista se sustenta en un punto de vista fundamentalmente antropocéntrico, donde la naturaleza es vista como un instrumento en beneficio del hombre, para ser explotada y mejorar la calidad material de la vida humana. En este modelo no se consideró un escenario de escasez de recursos y una vez que esta se presentó, tecnología e información cobraron importancia vital. (Bustillo \& Martínez, 2008, p.391)
\end{abstract}

En los años 80 este enfoque se transforma, y es con Amartya Sen (1987), con quien se logra una nueva perspectiva desde la cual el proceso de desarrollo se ve como un proceso de ampliación de las "capacidades" de las personas y no como un aumento de la utilidad y del bienestar y satisfacción económicos, únicamente, sino como la creación de las condiciones necesaria para que las personas logren sus capacidades. Con este nuevo concepto, el desarrollo no tiene como propósito ampliar la producción de los pueblos y países ni su sistema económico, sino lograr que las personas tengan más y mejores opciones para que tengan bienestar, felicidad y una vida más larga. En este orden, se entiende, por ejemplo, que tener una vida más larga implica acceder a condiciones de salud integral, tener bienestar implica tener acceso al conocimiento, tener felicidad implica disponer de opciones de acceso para el disfrute de la vida misma y estar en armonía con un planeta sostenible. Estas opciones para lograr todas las capacidades posibles deben darse en el marco de la libertad, y destacando que las capacidades y las opciones están íntimamente relacionadas y que ambas, a su vez, están estrechamente asociadas a la libertad; entendiendo la libertad de 
aspectos negativos que no aportan al logro de las capacidades, ejemplo: libre para decidir, libre para desplazarse, libre para estudiar, libre de hambre, libre de enfermedad evitable, libre para disfrutar tiempo propio, entre otras libertades.

Este nuevo concepto de desarrollo va en contravía del concepto sobre la riqueza, entendida como la acumulación de bienes materiales; por lo tanto, remplaza el concepto de acumular bienes por el de crear capacidades en los seres humanos, como lo diría Bourdieu (1999).

En este sentido, Nusbaum plantea:

Ante esta situación, la responsabilidad de toda la ciudadanía es asumir el deber de construir una sociedad en la que todos disfruten de unos mínimos de calidad de vida, en la que la justicia social sea una realidad sentida y vivida por la población, en la que el término «libertad» no se identifique con «elegir el producto de consumo» y se asocie a autonomía crítica, responsable y solidaria, en la que la participación sea cualificada y se anime a todos y no solo a un grupo privilegiado a tomar las riendas del devenir político. Habrá que comprometerse sinceramente en dejar ya a un lado democracias simplemente formales, y luchar por que la utopía democrática (fuerza de ideales como la participación activa, la igualdad civil, política y material, la libertad, la solidaridad, la justicia) deje de serlo para transformarse en una realidad más de nuestra vida cotidiana. (Guichot-Reina, 2015, p.12)

En este mismo sentido, la Corporación Juego y Niñez plantea, desde su Metodología Naves (Niños, Aprendiendo, Viviendo, Experimentando y Socializando), que el desarrollo humano se da en la medida en que se suplen unas necesidades que tienen que ver con el desarrollo del ser, el hacer y el estar de

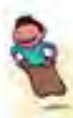


las personas. Implica una mirada en la que es necesario desarrollar unas capacidades y habilidades que le permitan al ser humano construirse como ciudadano y como un agente que construye su propio desarrollo.

Al respecto, Amtya Sen (1999) nos aporta con su planteamiento respecto a que la persona es un ser de necesidades múltiples e interdependientes, que pueden analizarse según unas categorías existenciales y otras axiológicas: unas referidas a las necesidades del Ser, Tener, Hacer y Estar y aquellas referidas a la subsistencia, protección, afecto, entendimiento, participación, ocio, creación, identidad y libertad.

A pesar de esta nueva manera de entender el desarrollo humano, uno de los interrogantes de mayor relevancia hoy tiene que ver con la manera en la cual los estados y las sociedades están dando opciones para que los niños y las niñas logren esas capacidades humanas, lo que les asegura un bienestar integral en el presente y en la configuración de un futuro pensado en lógica de este nuevo desarrollo.

\section{Los niños y adolescentes necesitan un conjunto equilibrado de habilidades cognitivas, sociales y emocionales para tener éxito en la vida moderna. Las habilidades cognitivas se han demostrado necesarias para influir en la probabilidad de éxi- to educativo y en el éxito en el mercado laboral de cara hacia el futuro. A su vez, las habilidades sociales y emocionales, tales como la perseverancia, la sociabilidad y la autoestima se ha demostrado que influyen en numerosas medidas en los resultados sociales. (UNESCO-OCDE, 2016, p.1)}

Podría decirse que las habilidades cognitivas y socioemocionales, al interactuar, generan un conjunto de herramientas propicias para fortalecer la auto- 
nomía en los niños y posibilitan el tener una probabilidad de mayor éxito en las escuelas, en sus barrios, en sus veredas, en las comunidades, en sus ciudades y en su país. El reto que impone esta perspectiva implica un cambio radical en la manera de entender y desarrollar los procesos educativos y de formación, e incluso en la manera de medir y evaluar dichos procesos.

En este sentido, el llamado es a destacar la formación axiológica y existencial, es decir, "esa educación y formación desde las habilidades y capacidades que favorecen los procesos de socialización, aquellos aprendizajes que movilizan directamente el ser, el hacer y el estar en el mundo" (Corporación Día de la Niñez, 2014, p.14). Hoy se estima más a las personas por lo que saben y la suma de sus conocimientos que por su capacidad de valorar y transformar su mundo en condiciones de equilibrio y equidad, condición esencial que se traduce en la capacidad de dar sentido a la existencia humana.

Es aquí donde la Corporación Juego y Niñez propone el programa Ludotecas Naves (niños y niñas aprendiendo, viviendo, experimentando y socializando) como un programa social orientado a favorecer el desarrollo de esas habilidades y capacidades en los niños y las niñas y en todos los participantes, pues se trata de un equipamiento integral entre ludotecario, ambientes de juego, metodología y materiales que, articulados como un sistema pedagógico, mira al niño y la niña como seres integrales capaces de proponer, crear, construir, reconocer en los otros estas mismas capacidades, acordar y comprometerse con los aprendizajes fundamentales que va incorporando.

En este orden es preciso plantearnos que una ludoteca es esencialmente un programa de desarrollo integral desde el juego, que de manera inherente genera aprendizajes centrados en la construcción personal, moral y social que potencia el desarrollo de los niños y las niñas y, por lo tanto, el desarrollo humano.






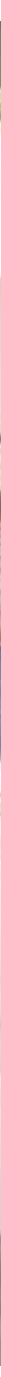


Un ejemplo de esto es lo que sucede en una ludoteca NAVES en Manaure, que funciona hace 18 años en este municipio, y que ha logrado, a partir del reconocimiento de su cultura y del reconocimiento de los niños y las niñas como sujetos activos y transformadores, lugares de participación efectiva, como la radio, en donde ellos y ellas tienen la posibilidad de reflexionar y compartir las reflexiones sobre su realidad y cómo transformarla. Otro ejemplo es lo que sucede en la ludoteca NAVES de Chinchiná, en donde los niños y las niñas comprenden el sentido que tiene establecer acuerdos para el uso de la ludoteca y que se traspone a los acuerdos que se han construido para convivir en sociedad y crecer como ciudadanos, desde el enfoque de convivencia que se le ha dado a la propuesta pedagógica en la cual el juego es un lenguaje que permite las formas positivas de relación, aun en la presencia del conflicto, el cual no se niega ni se evade, sino que se gestiona entre todos. De esto podemos decir que los niños, mediante el juego, acompañados de personas expertas jugadoras e innovadoras, aprenden a resolver cuestiones y situaciones que entrañan una gran complejidad como seres humanos: convivir pacíficamente, concertar y decidir, comunicar y expresar los sentimientos asertivamente, asumir compromisos, respetar los derechos de los demás y a ejercer los propios con responsabilidad, a resolver los conflictos por medio de formas no violentas ni discriminatorias y excluyentes, y a construir con el otro para aportar a la solución de los problemas que colectivamente nos afectan día a día.

Los niños, al jugar, comprenden e incorporan valores para su vida, reflexionan más y desarrollan, con creatividad, respuestas afirmativas frente a situaciones concretas de su vida cotidiana, porque al desarrollar estas habilidades están en la capacidad de relacionar y poner en práctica todo ese saber-hacer desde su ser. Estos aprendizajes favorecen en los niños y jóvenes el saber trabajar en equipo, a cooperar y ayudar especialmente a los más pequeños, a saber cómo pedir ayuda, a saber seguir instrucciones en las rutinas escolares, a manejar sus

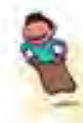


emociones, a entender las perspectivas de los otros y a poder negarse apropiada y asertivamente a las peticiones de otros (Borja, 1994).

Frente a esto, un encuentro de juego en la ludoteca o un día viviendo la propuesta que esta tiene puede constituirse en una experiencia en la cual desde la llegada a la puerta de entrada, como sucede en la ludoteca NAVES de Purificación - Tolima, es un momento en el cual se reconoce a otro legítimo en la convivencia (Maturana, 2001), a un otro que se recibe con afecto, con respecto y con la naturalidad que otorga el encuentro con un amigo; posteriormente, el juego que se favorece allí es un juego que reta a vivir una aventura lúdica que puede ser desde un juego de la tienda, construyendo juntos acuerdos para comprar y vender y agotar las existencias y volver a surtirla, hasta un viaje interespacial, en donde los jugadores astronautas se obligan a pensar en un mundo posible anticipando sucesos y acontecimientos que retarán el más alto grado de imaginación. O como lo que sucede en la ludoteca NAVES de Quibdó, en donde el movimiento y el ritmo se hace presente al jugar a montar coreografías con la música construida con los ritmos y los instrumentos propios de este Pacífico colombiano, desplegando todas las capacidades de expresión del cuerpo con voces, aplausos, pataleos, retahílas que terminan en una única risa colectiva. 0 lo que ocurre en San Andrés, cuando se juega con la arena del mar de los siete colores que se combina con los colores de un juguete girador que obliga a los participantes a mantenerse juntos en una secuencia y movimiento para cuidar que la pelota no se vaya al mar y que, al final, resulta tendido en la arena para todos sentarse sobre él y conversar sobre lo sucedido y disfrutado. Y al salir, después de este espacio de juego, alegría, retos, vértigo, imaginación, creatividad, es posible conversar de manera tranquila para crear acuerdos respecto a lo logrado en el juego y asumir compromisos para un nuevo regreso, lo que se constituye en un pacto que sella la relación de convivencia que se va construyendo. 
Estas historias y miles más se tejen en el contexto de una ludoteca, y el juego que estas proponen a los niños y a las familias constituyen una gran oportunidad de encuentro y de socialización, en donde el aprendizaje, mucho más allá del conocimiento que cada niño o niña puedan adquirir (que ya de por sí es mucho), permite un desarrollo del ser, un aprendizaje existencial, que recobra la pregunta por el sentido: el sentido de la vida, de la política, de la participación, de la solidaridad, de la amistad, de la ética, de la justicia, de la paz.

En este sentido "este espacio para el juego trasciende la función de guardar juguetes hacia una propuesta pedagógica y formativa mucho más profunda" (Corporación Día de la Niñez, 2009, p.53), por esto, la ludoteca "debe ser comprendida como una herramienta, como un pretexto, como un espacio de mediación del juego para formar y educar" (Ibíd., p.65).

Podría decirse que en estas ludotecas se aprende a ser crítico, a ser autónomo, a pensar en libertad, a expresar, a disentir, a distinguir entre lo justo e injusto, entre lo que está bien y lo que está mal. Los niños, las niñas y las familias que participan en las ludotecas aprenden a ser solidarios, a dialogar, a respetar las ideas y pensamientos del otro pese al disenso, a participar y a distinguir que todos somos diferentes, pero compartimos muchas cosas en común que nos enriquecen y nos complementan como seres humanos.

Cuando los niños y las niñas acceden a la posibilidad de esta formación existencial pueden participar de la transformación de sus vidas desde la casa, la escuela, el barrio, la calle y en cualquier escenario o situación en los cuales deban decidir, en donde su voz y voto sean decisivos, en donde sus actos marquen la diferencia y, por ello, en donde las consecuencias de lo que hagan cambien y aporten a la construcción del gran proyecto colectivo, en donde cada uno avanza hacia su desarrollo y aporta al desarrollo de los demás y al desarrollo humano.




Entender el desarrollo de esta manera es retar a una sociedad a comprender el valor de lo fundamental del juego, de la risa, del abrazo, del encuentro con otros, de la conversación, del acuerdo, del compromiso consigo mismo y con los otros. Implica el desafío de entender que los niños y las niñas crecen, pero que el adulto también lo hace, de entender que el desarrollo es ancho, profundo y con múltiples aristas, de comprender que el respeto a los desarrollos particulares es un indicador de desarrollo social, de entender que el ser humano requiere reencontrarse con el juego desde el juego y de comprender que una ludoteca -más que un lugar para disponer juguetes- es una alternativa posibilitadora para lograr esas comprensiones, constituyéndose en un programa a la medida del ser humano. 
